\title{
CÁlCULO ATUARIAL DE PROJEÇÃo DE RECEITAS E CUSTOS DAS PENSÕES DOS MILITARES DAS FORÇAS ARMADAS DO BRASIL
}

\author{
Thierry Faria da Silva Gregorio \\ Universidade do Estado do Rio de Janeiro e Centro de Análises de Sistemas Navais \\ e-mail: thierrygregorio@ime.uerj.br \\ Ronaldo Cesar Evangelista dos Santos \\ Centro de Análises de Sistemas Navais \\ e-mail: ronaldo@casnav.mar.mil.br \\ Ernesto Rademaker Martins \\ Centro de Análises de Sistemas Navais \\ e-mail: rademaker@casnav.mar.mil.br
}

\begin{abstract}
RESUMO
Neste artigo são apresentados os principais estudos atuariais que são realizados periodicamente no Sistema Atuarial das Pensões Militares das Forças Armadas do Brasil. Considera-se esta abordagem de alta relevância para o meio acadêmico e professional devido a grande escassez de material bibliográfico sobre as técnicas atuariais. Neste sentido, o trabalho atual apresenta algumas análises sobre a base de dados utilizada, estudos de testes de aderência utilizando o método Qui-Quadrado, estudo de composição familiar, taxa de crescimento salarial e projeção atuarial de receitas e despesas considerando o horizonte temporal de 75 anos.
\end{abstract}

\section{Introdução}

Anualmente é realizada a Avaliação Atuarial das Pensões Militares das Forças Armadas com o objetivo de atender as necessidades do Ministério da Defesa (MD) de apresentar aos órgãos fiscalizadores e ao Ministério do Planejamento, Orçamento e Gestão (MPOG) os resultados atuariais dos compromissos da União com os benefícios pagos pelo Sistema de Pensões dos Militares das Forças Armadas (FFAA).

O propósito é avaliar as receitas e os custos do referido sistema em um horizonte de 75 anos, empregando-se a ciência atuarial. Esta análise se restringe às pensões militares definidas pela Lei $\mathrm{n}^{\circ} 3.765$, de 4 de maio de 1960, para as quais existe a contribuição regular compulsória de militares ativos e inativos, cuja alíquota é de 7,5\%.

As pensões militares são financiadas pelo regime financeiro de repartição simples. Tal fato decorre do disposto no artigo 32 da Lei $\mathrm{n}^{\circ} 3.765$, de 1960.

No sistema de pensão militar, não há patrimônio acumulado para arcar com os custos futuros sendo, portanto, financiado por regime orçamentário, ou seja, sem acúmulo de capital.

Para condução da aplicação da ciência atuarial aos custos das pensionistas, necessitase estudar e projetar os custos constitucionais dos atuais ativos, inativos e pensionistas.

Os dados cadastrais individuais utilizados neste estudo são referentes às bases de dados de outubro de 2014 e foram consideradas satisfatórias para o desenvolvimento dos cálculos e respectivas projeções atuariais de receitas e despesas, como serão apresentados 
oportunamente.

Os cálculos seguem rígida norma atuarial nos processos de tratamento de dados disponibilizados pelas Forças Armadas (Marinha do Brasil, Exército Brasileiro e Força Aérea Brasileira), constando as tendências de comportamento da massa populacional estudada.

\section{Bases de Dados Utilizadas}

Para a produção deste estudo, foram usados os dados da base BIEG (Banco de Informações Estratégicas e Gerenciais), que reúne informações financeiras dos militares, e da base Extra-BIEG (base de dados complementar ao BIEG), que contém informações biométricas e históricas de ativos, inativos e pensionistas. Estes documentos são controlados por contemplarem informações pessoais dos militares das Forças Armadas.

Esses dados anualmente sofrem rigorosas análises qualitativa e quantitativa, no intuito de confirmar a consistência das informações, pelas técnicas de verificação e validação, evitando arraste de erros para o cálculo atuarial.

\section{Resumo Estatístico das Populações de Ativos, Inativos e Pensionistas}

A análise estatística de uma população e a sua respectiva análise financeira possibilitam identificar determinadas características que auxiliam na compreensão dos resultados atuariais e servem de base para a correta tomada de decisões, objetivando a manutenção do sistema.

Foram utilizadas informações individuais dos militares ativos, inativos e dos pensionistas, referentes à Marinha do Brasil, ao Exército Brasileiro e à Força Aérea Brasileira para que fosse possível realizar as análises.

Para cada militar ativo e inativo existem 0,41 pensionistas nas Forças Armadas, distribuídas conforme a proporção apresentada a seguir: Marinha do Brasil: 0,4598; Exército Brasileiro: 0,4421 e Força Aérea Brasileira: 0,3031.

Em relação à folha do mês dos bancos de dados de referência, a soma da folha de remuneração de militares ativos e inativos equivale a 2,20 vezes a folha mensal de pensão das Forças Armadas. Esta proporção se comporta da seguinte forma: Marinha do Brasil: 2,46; Exército Brasileiro: 1,81 e Força Aérea Brasileira: 3,19.

\begin{tabular}{|l|l|l|l|l|}
\hline \multicolumn{1}{|c|}{ Tipo } & Quantidade & Folha Mensal & $\begin{array}{c}\text { Remuneração/ } \\
\text { Provento }\end{array}$ & $\begin{array}{c}\text { Idade } \\
\text { média }\end{array}$ \\
\hline Ativos & 370.389 & $\mathrm{R} \$ 1.266 .935 .317,16$ & $\mathrm{R} \$ 3.420,55$ & 27 \\
\hline Inativos & 148.393 & $\mathrm{R} \$ 1.263 .161 .066,77$ & $\mathrm{R} \$ 8.512,27$ & 63 \\
\hline Pensionistas & 216.659 & $\mathrm{R} \$ 1.151 .152 .627,74$ & $\mathrm{R} \$ 5.313,20$ & 65 \\
\hline
\end{tabular}

Tabela 1. Estatísticas das Populações analisadas

De acordo com a Tabela 2, dentre os militares ativos na data base de outubro de 2014, 49.945 contribuem com $1,5 \%$ além dos $7,5 \%$, o que permite que a filha tenha uma pensão vitalícia. Tal quantidade equivale a $13,48 \%$ dos militares ativos. Estas proporções tem a tendência de redução contínua a cada ano, pois tal opção cessou em 29 de dezembro de 2000. Os militares que estavam na ativa à época vão ingressando na inatividade gradualmente e os militares que ingressaram após tal data não podem optar pela opção de contribuir com 1,5\% além dos 7,5\%, o que permitia que a filha tivesse uma pensão vitalícia. 


\begin{tabular}{|c|c|c|c|}
\hline Força Armada & $\begin{array}{c}\text { Quantidade de } \\
\text { militares }\end{array}$ & $\begin{array}{c}\text { Quantidade que } \\
\text { contribui com 1,5\% }\end{array}$ & $\begin{array}{c}\text { Percentual que } \\
\text { contribui com 1,5\% }\end{array}$ \\
\hline Marinha do Brasil & 81.477 & 12.231 & $15,01 \%$ \\
\hline Exército Brasileiro & 218.764 & 25.981 & $11,88 \%$ \\
\hline Força Aérea & 70.148 & 11.733 & $16,73 \%$ \\
\hline
\end{tabular}

Tabela 2. Descrição da População de Ativos por Força Armada

Dentre os atuais inativos, 111.997 optaram, conforme artigo 31 da Medida Provisória $\mathrm{n}^{\circ}$ 2.215-10 de 31 de agosto de 2001, pela contribuição de 1,5\%, o que lhes dá o direito a gerar pensão vitalícia para as filhas. Esta quantidade equivale a 75,47\% dos militares inativos. Esta proporção se comporta como apresentado na Tabela 3, em cada Força Armada.

\begin{tabular}{|c|c|c|c|}
\hline Força Armada & $\begin{array}{c}\text { Quantidade de } \\
\text { militares inativos }\end{array}$ & $\begin{array}{c}\text { Quantidade que } \\
\text { contribui com 1,5\% }\end{array}$ & $\begin{array}{c}\text { Percentual que } \\
\text { contribui com 1,5\% }\end{array}$ \\
\hline Marinha do Brasil & 46.726 & 32.824 & $70,25 \%$ \\
\hline Exército & 64.068 & 49.901 & $77,89 \%$ \\
\hline Força Aérea & 37.599 & 29.272 & $77,85 \%$ \\
\hline
\end{tabular}

Tabela 3. Descrição da População de Inativos por Força Armada

Considerando o conjunto de militares ativos e inativos, o total de 161.942 militares ainda poderão gerar pensões vitalícias para filhas.

\section{Definição das Tábuas Biométricas por meio do Teste Qui-Quadrado}

De acordo com a resolução CNPC n ${ }^{\circ}$ 09, de 29 de novembro de 2012, Publicado no D.O.U. no 16 , de 23 de janeiro de 2013, seção I:

"2.4. A adequação da tábua biométrica utilizada para projeção de longevidade deverá ser atestada por meio de estudo específico cujos resultados comprovem a aderência, nos três últimos exercícios, entre o comportamento demográfico da massa de participantes e assistidos vinculados ao plano e a respectiva tábua biométrica utilizada."

Cabe destacar que o mercado previdenciário utiliza o teste qui-quadrado com frequência. Portanto, no intuito de validar o referido estudo, optou-se por realizar os testes de aderência pelo método qui-quadrado, pois é comprovadamente eficiente em testes de aderência.

Por meio dessa metodologia de análise de adequação de hipóteses, os desvios observados entre o número de eventos efetivamente ocorridos e aqueles estimados por determinado padrão são avaliados quanto à sua significância, através de valores tabelados de uma distribuição qui-quadrado.

O objetivo deste método é comparar as divergências entre as frequências esperadas (E) e observadas (O), considerando como observados os óbitos, ou entradas em invalidez, ocorridos entre 2011 e 2013 inclusive, para cada faixa etária, na população de ativos, inativos e pensionistas.

Adicionalmente, os óbitos ou entrada em invalidez são estimados, multiplicando as probabilidades associadas a cada idade, de acordo com as tábuas, pela quantidade de indivíduos expostos ao risco desta mesma população.

Para testar se as discrepâncias calculadas possuem significância estatística, calcula-se 
o índice $\chi^{2}$ e compara-se com o mesmo fator ( $\chi 2$ crítico) obtido da tabela de distribuição quiquadrado.

Para obtenção dos resultados foi adotado nível de significância de 5\%, ou seja, probabilidade de $5 \%$ de rejeição da hipótese nula, a qual considera que a frequência observada é igual à frequência esperada. $\mathrm{O}$ índice $\chi 2$ é calculado pela fórmula a seguir:

$$
x^{2}=\sum \frac{(O-E)^{2}}{E}
$$

Sendo,

$\mathrm{O}=$ Frequência Observada

$\mathrm{E}=$ Frequência Esperada

Quanto menor a divergência entre a frequência observada e a frequência esperada, menor a estatística $\chi^{2}$ e maior a probabilidade de não se rejeitar a hipótese de aderência entre a experiência de mortalidade real e a tábua adotada como premissa.

Após o cálculo do $\chi 2$, verifica-se o $\chi 2$ crítico levando-se em consideração o nível de significância adotado e os graus de liberdade considerados no teste. No estudo, cada faixa etária representa uma observação independente da amostra. Sendo assim, o número de graus de liberdade da estatística $\chi 2$ é representado pelo número de faixas etárias utilizadas subtraídas de um, devido à característica intrínseca do modelo de teste utilizado.

\subsection{Resultados de Mortalidade de Ativos e Inativos das Forças Armadas}

Para a população de ativos e inativos das três Forças, duas tábuas se aderiram à mortalidade observada para o período de 2011 a 2013, para as idades entre 25 e 90 anos:

- UP-94 MT-M-ANB suavizada em 27\% com estatística qui-quadrado de 72,5034;

- UP-94 Homens desagravada em 27\% com estatística qui-quadrado de 72,5072.

A tábua adotada foi a UP-94 MT-M-ANB suavizada em $27 \%$ por possuir a melhor aderência, como demonstrado no Gráfico 1 . A estatística qui-quadrado crítica foi de 84,82.

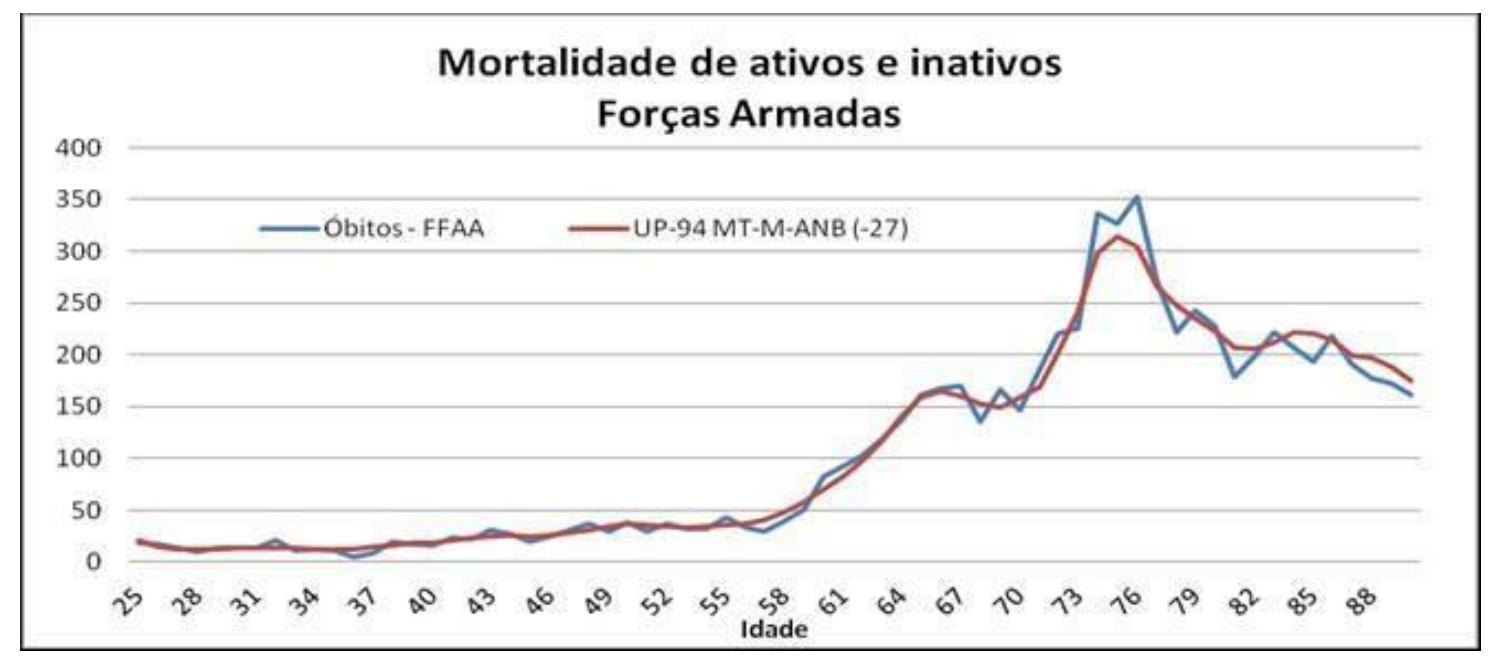

Gráfico 1. Aderência de Mortalidade de Ativos e Inativos - Forças Armadas 


\subsection{Resultados de Mortalidade de Inválidos das Forças Armadas}

Para a população de inválidos das Forças Armadas, para o período de 2011 a 2013, duas tábuas aderiram às ocorrências de falecimento, são elas:

- HUNTER'S agravada em $82 \%$ com estatística 29,31 ;

- HUNTER'S agravada em 75\% com estatística 30,16.

A tábua adotada foi a HUNTER'S agravada em $82 \%$ por possuir a melhor aderência, como apresentado no Gráfico 2. Para conseguir esta aderência foi necessário analisar exclusivamente o intervalo de idades entre 25 e 60 anos. A estatística qui-quadrado crítica foi de 50,99 .

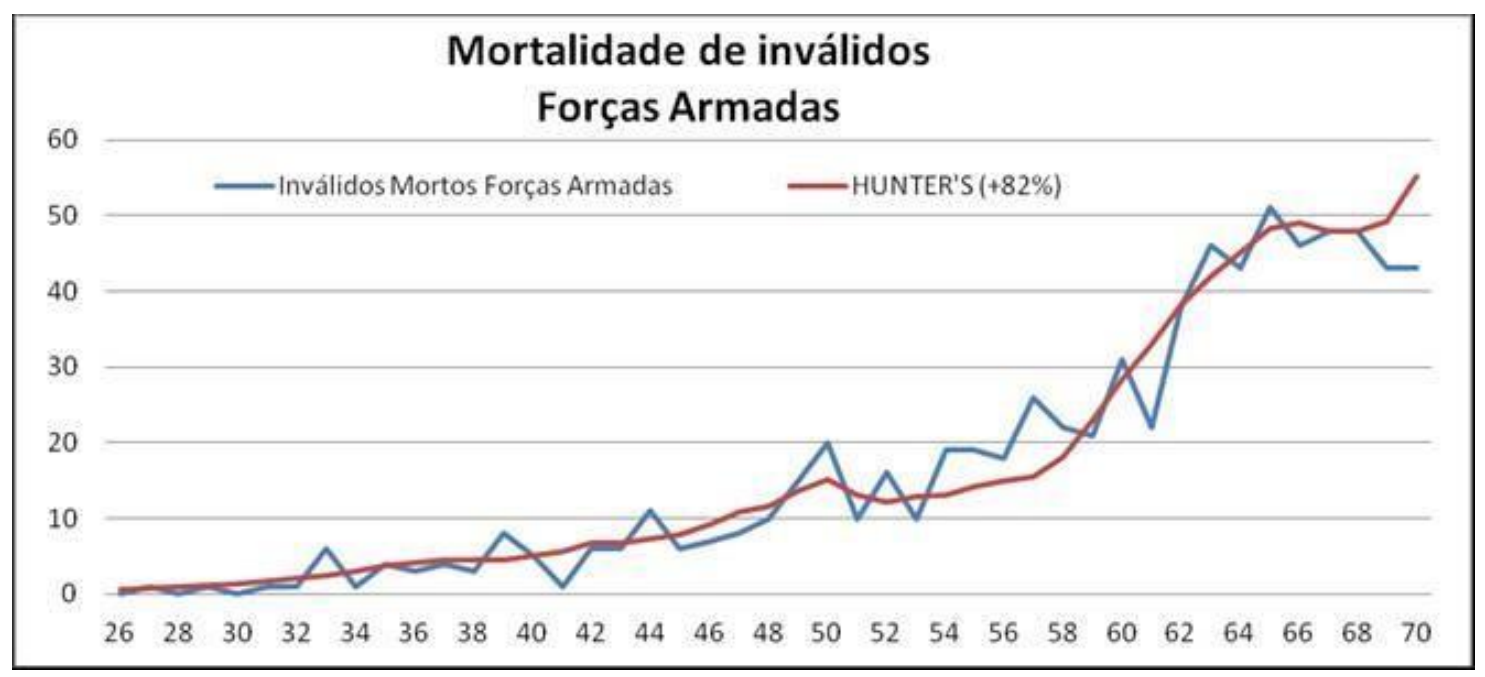

Gráfico 2. Aderência de Mortalidade de Inválidos - Forças Armadas

\subsection{Resultados de Entrada em Invalidez das Forças Armadas}

No caso da população de ativos das Forças Armadas, para o período de 2011 a 2013, apenas uma tábua aderiu às ocorrências de entrada em invalidez, conforme demonstrado no Gráfico 3:

- MULLER com estatística 30,21.

Para conseguir aderência a tábua MULLER foi necessário analisar exclusivamente o intervalo de idades entre 30 e 50 anos, caso contrário não haveria aderência a nenhuma tábua atuarial disponível. A estatística qui-quadrado crítica foi de 31,41. 


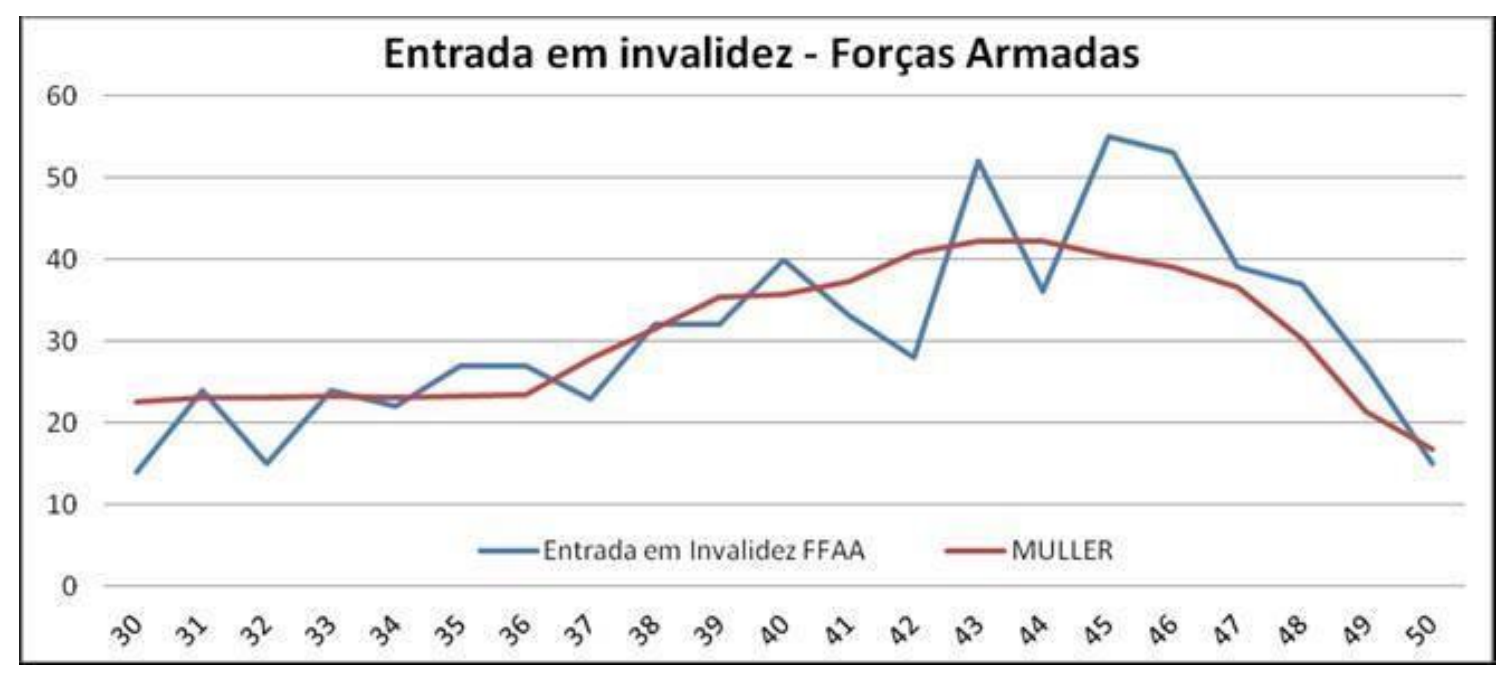

Gráfico 3. Aderência de Entrada em Invalidez - Forças Armadas

\section{Composição Familiar do Militar}

Com o objetivo de calcular o custo com as pensões das Forças Armadas é de suma importância estimar as probabilidades de que um militar venha a gerar uma pensão vitalícia ou temporária no momento de seu falecimento. Além disto, faz-se necessário saber a idade esperada deste potencial pensionista para estimar a duração da pensão. Portanto, utilizando as bases de dados BIEG e Extra-BIEG foram estimadas tais probabilidades e idades, que estão explicadas a continuação.

\subsection{Pensão Normal}

Pensão Normal é definida como aquela em que o potencial instituidor se tornou militar após o dia 29 de dezembro de 2000 e aqueles que ingressaram antes daquela data, mas optaram por não aderir à contribuição de $1,5 \%$, de acordo com o preconizado no artigo 31 da Medida Provisória no 2.215-10, de 2001.

A principal característica da pensão normal é a filha ter direito somente ao benefício temporário de pensão, ou seja, até completar 24 anos.

O Gráfico 4 representa as estimativas para a família do militar na data projetada de óbito. Para cada idade do instituidor militar foi calculada uma probabilidade de deixar beneficiário de pensão vitalícia (cônjuge) ou temporária (filho ou filha). 


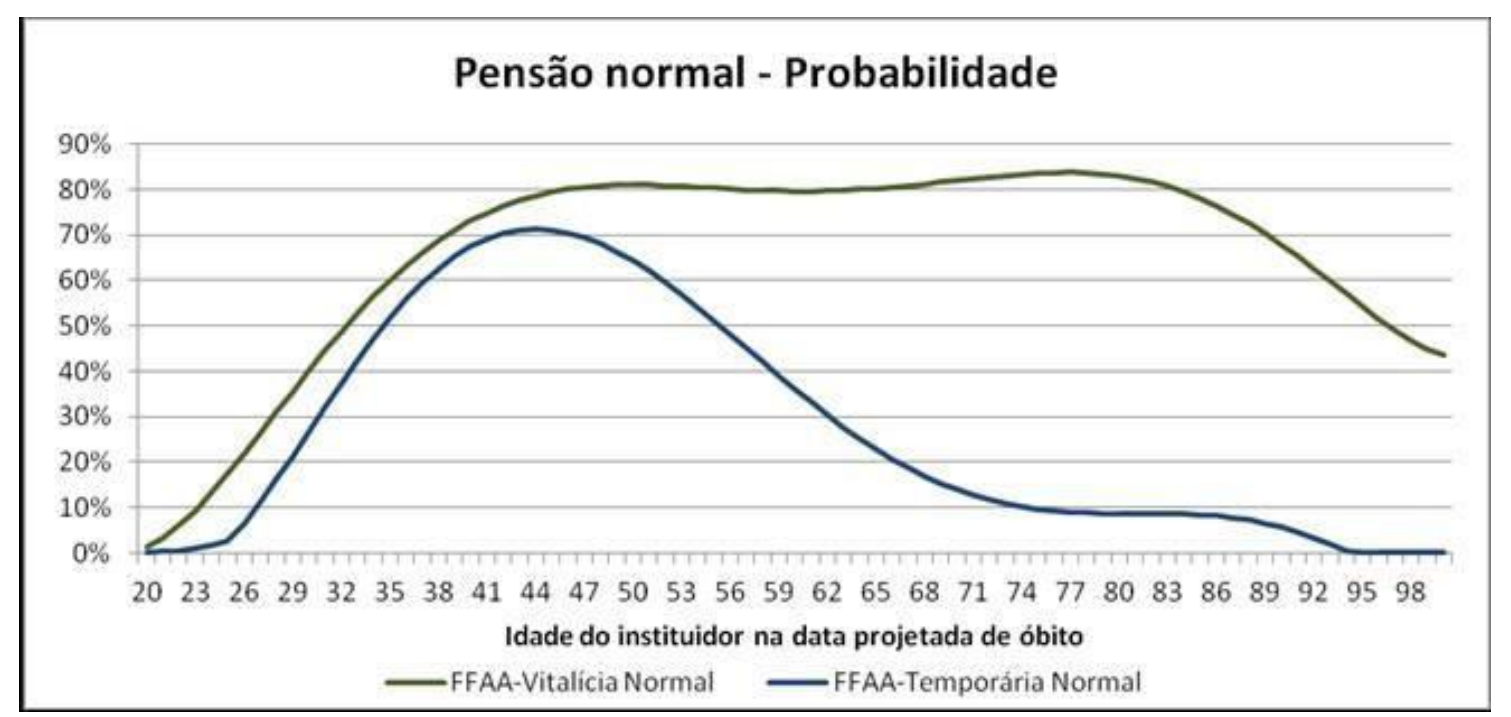

Gráfico 4. Pensão Normal - Probabilidades - FFAA

Para cada idade do militar instituidor foi estimada a idade do beneficiário mais novo de pensão vitalícia ou temporária, conforme apresentado no Gráfico 5.

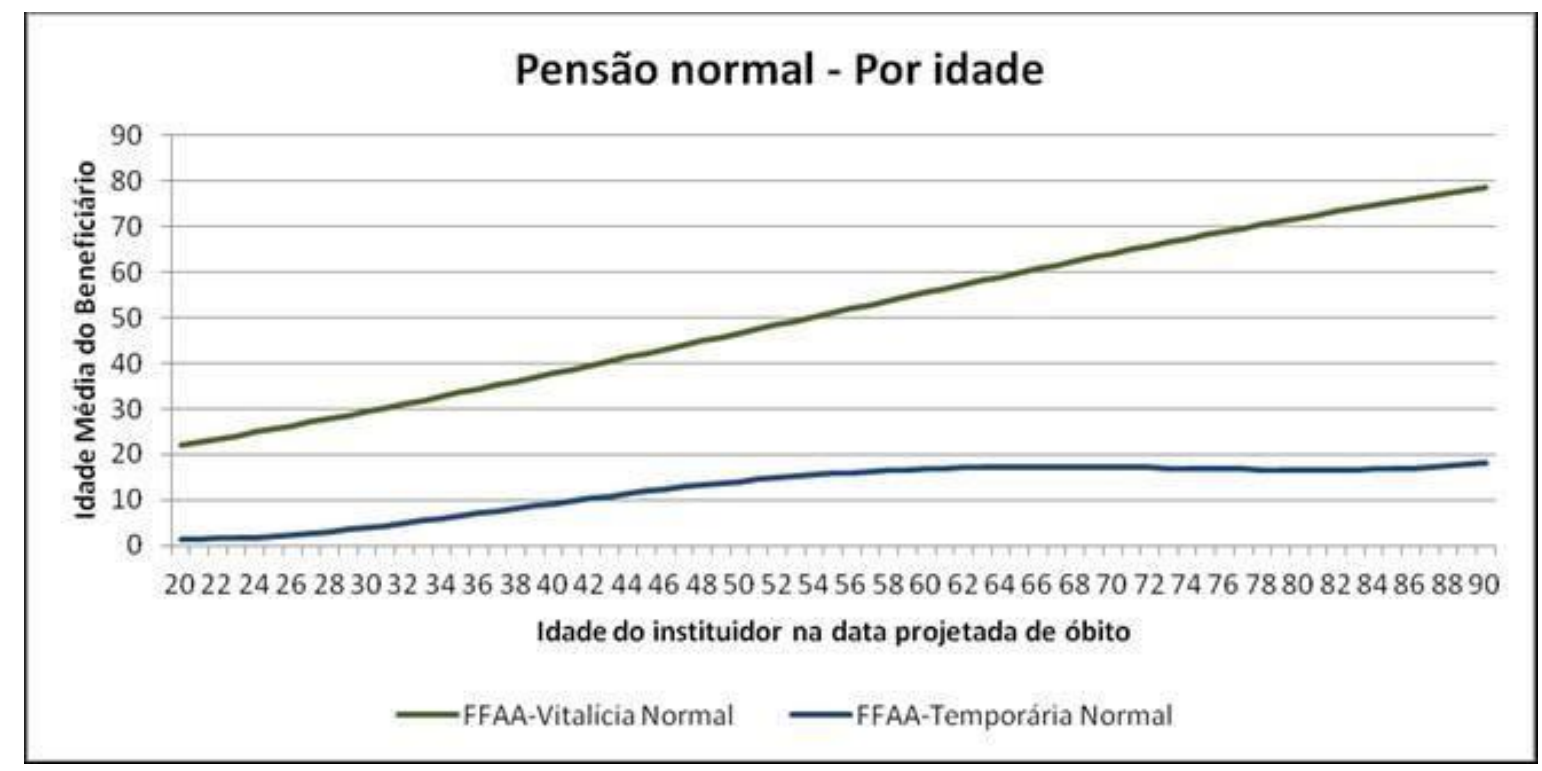

Gráfico 5. Pensão Normal - Idades - FFAA

\subsection{Pensão Extraordinária}

Pensão Extraordinária é definida como aquela em que os potenciais instituidores são os militares ativos e inativos que ingressaram até o dia 29 de dezembro de 2000, e aderiram ao dispositivo do artigo 31 da Medida Provisória $\mathrm{n}^{\circ}$ 2.215-10, de 2001, realizando contribuição mensal adicional de 1,5\%. A diferenciação característica da pensão extraordinária é a filha ter direito à pensão vitalícia.

O Gráfico 6 representa a probabilidade, para cada idade do instituidor, que contribui com 1,5\%, de deixar beneficiário de pensão vitalícia (cônjuge ou filha) ou temporária (filho), na data projetada do seu óbito.

Pode-se constatar que para este grupo de instituidores, entre as idades de 39 e 88 anos, há a probabilidade de deixar pensão vitalícia para filha ou cônjuge, acima de $80 \%$, o que 
contrasta com a baixa probabilidade de deixar pensão temporária para filho.

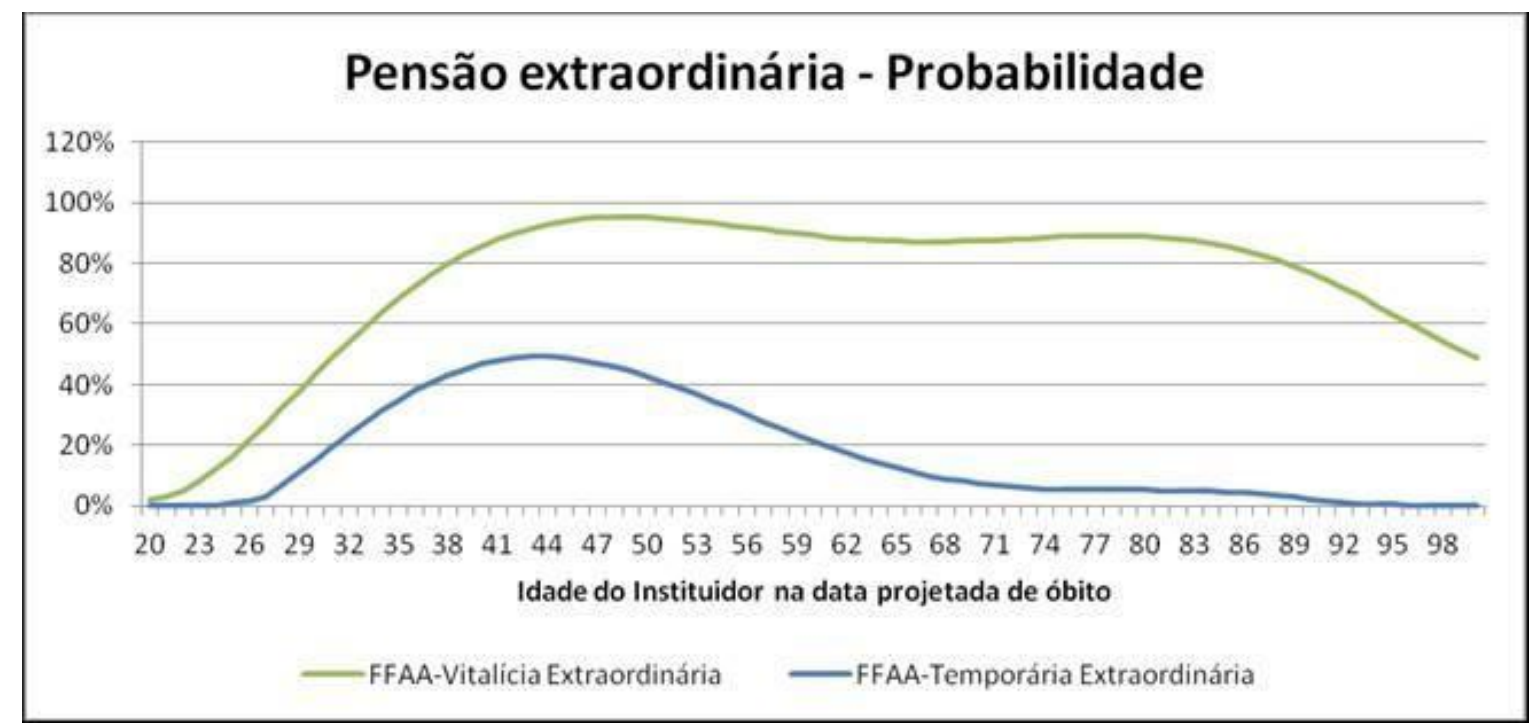

Gráfico 6. Pensão Extraordinária - Probabilidades - FFAA

O Gráfico 7 representa as características esperadas de idade para o pensionista do militar na data projetada de óbito. Para cada idade do militar foram estimadas as idades dos beneficiários mais novos de pensão vitalícia ou temporária.

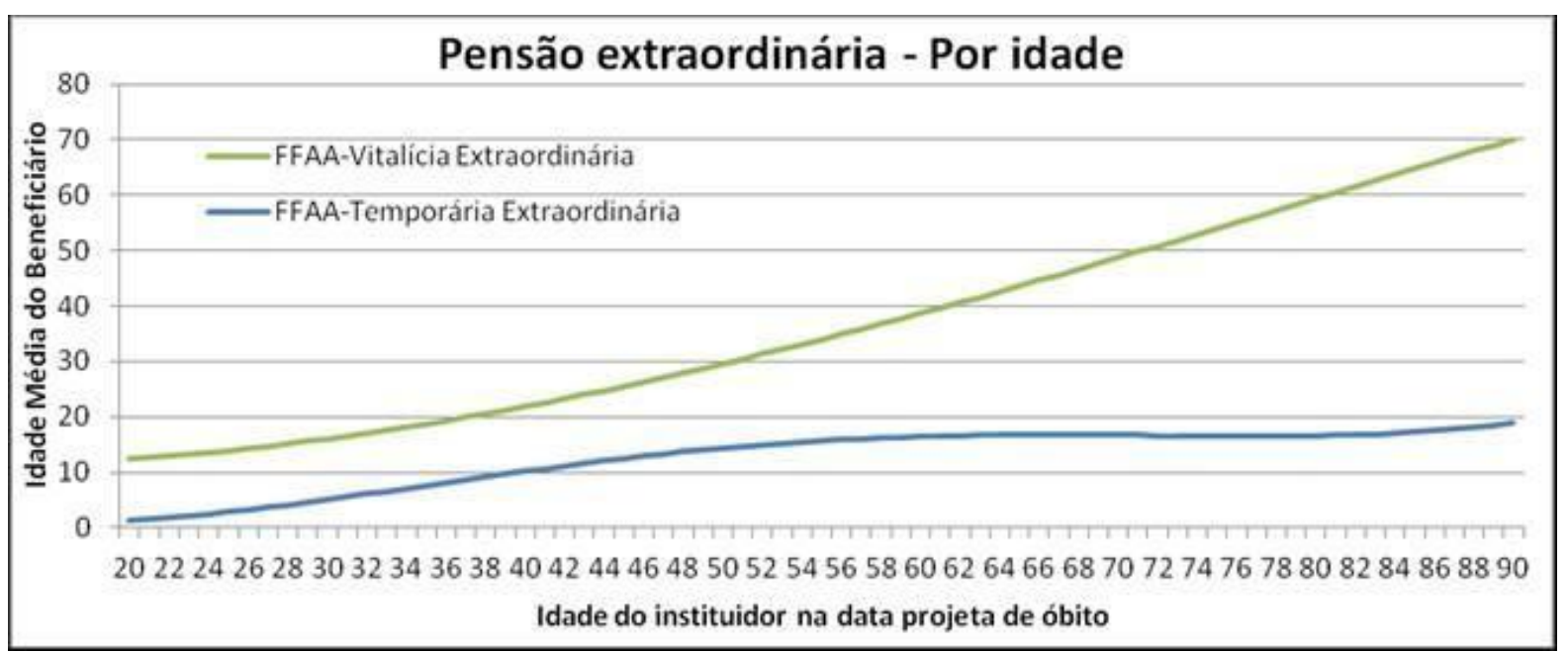

Gráfico 7. Pensão Normal - Idades - FFAA 


\section{Definição da Taxa de Crescimento Salarial}

Para lograr a taxa de crescimento salarial dos militares foram utilizados os dados remuneratórios de 370.389 ativos das Forças Armadas, os quais estão subdivididos entre praças e oficiais, conforme apresentado na Tabela 4.

\begin{tabular}{|c|c|c|c|c|c|}
\hline Força & $\begin{array}{c}\text { Total de } \\
\text { ativos }\end{array}$ & $\begin{array}{c}\text { Ativos com } \\
\text { remuneração } \\
\text { básica }\end{array}$ & $\begin{array}{c}\text { Praças com } \\
\text { remuneração } \\
\text { básica }\end{array}$ & $\begin{array}{c}\text { Oficiais com } \\
\text { remuneração } \\
\text { básica }\end{array}$ & $\begin{array}{c}\text { Registros } \\
\text { utilizados }\end{array}$ \\
\hline MB & 81.477 & 78.097 & 68.026 & 10.071 & 78.097 \\
\hline EB & 218.764 & 216.182 & 189.013 & 27.169 & 216.182 \\
\hline FAB & 70.148 & 69.357 & 58.479 & 10.878 & 69.357 \\
\hline Total & 370.389 & 363.636 & 315.518 & 48.118 & 363.636 \\
\hline
\end{tabular}

Tabela 4. Total de Registros Utilizados - FFAA

Como a praça entra nas Forças Armadas em média aos 20 anos e permanece no serviço ativo em geral por 30 anos, ao comparar a curva de salários médios nominais por idade, no intervalo entre 20 e 50 anos, com a regressão linear obteve-se o comportamento apresentado no Gráfico 8. Para elaborar tal gráfico foram utilizadas as remunerações dos 315.518 praças das Forças Armadas da ativa que possuem a parcela remuneração básica.

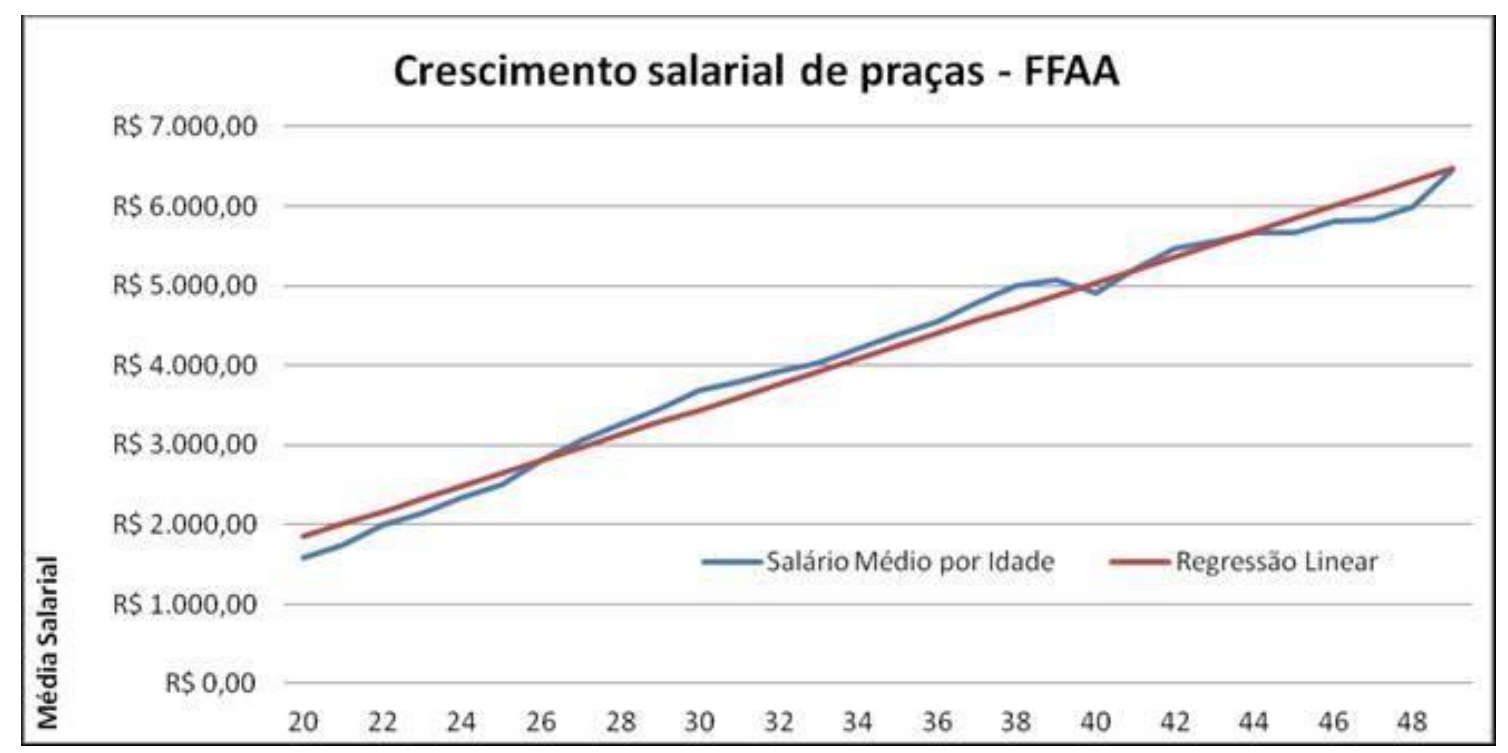

Gráfico 8. Curva de Salários Médios de Praças por Idade - FFAA

Como o oficial entra nas Forças Armadas em média aos 23 anos e permanece no serviço ativo em geral por 30 anos, ao comparar a curva de salários médios nominais por idade, no intervalo entre 23 e 53 anos, com a regressão linear obteve-se o comportamento, conforme descrito no Gráfico 9. Para elaborar tal gráfico foram utilizadas as remunerações dos 48.118 oficiais das Forças Armadas da ativa que possuem a parcela remuneração básica. 


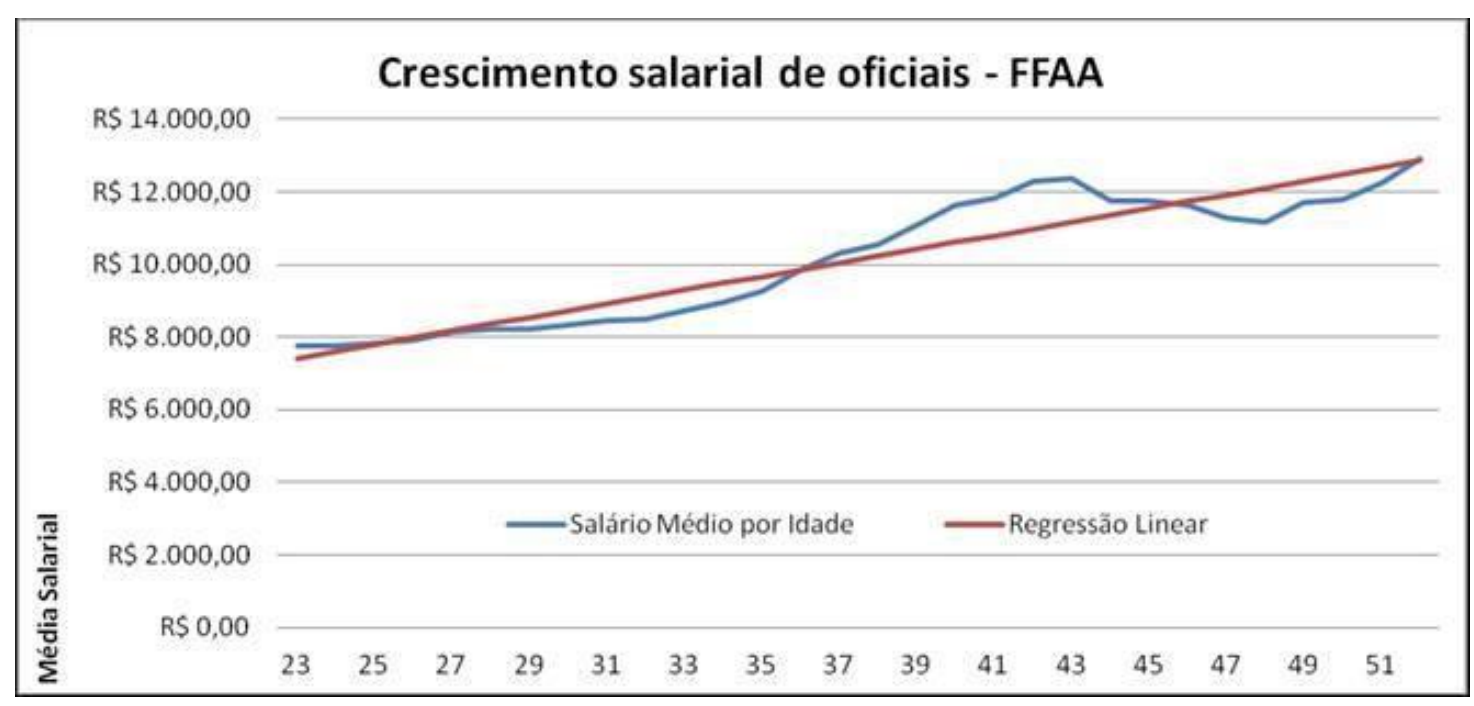

Gráfico 9. Curva de Salários Médios de Oficiais por Idade - FFAA

Dividindo-se o salário referente à idade em que se espera que o militar se transfira para a inatividade (50 anos para praça e 53 anos para oficial) pelo salário de cada idade, podese projetar o crescimento salarial esperado na carreira.

Apurando-se o Crescimento Salarial Anual (CSA) esperado para cada idade e, posteriormente, calculando-se a média ponderada, encontra-se o percentual de $3,83 \%$ a.a. para praças e $2,47 \%$ a.a. para oficial.

Este valor é um valor nominal de crescimento salarial. Admitindo-se uma inflação anual de 5,5\%, medida pelo IPCA, o crescimento real anual de salário seria de $-1,59 \%$ para praças e $-2,88 \%$ para oficiais. Considerando que a resolução CNPC $\mathrm{n}^{\circ} 15$, de 19 de novembro de 2014, não autoriza o uso de crescimento salarial negativo, este estudo considera o crescimento real anual de salário ou de benefícios de $0,0 \%$.

\section{Projeções Atuariais de Pensionistas - Forças Armadas}

A projeção de arrecadação e do custo com pensões tem como objetivo conferir transparência e previsibilidade às obrigações das Forças Armadas, de forma a orientar a formulação de políticas para manter a sustentabilidade fiscal de longo prazo.

Estes resultados representam a integração de receitas e custos tanto do grupo dos benefícios a conceder (atuais ativos e futuros inativos) como do grupo dos benefícios concedidos (atuais inativos e atuais pensionistas). O Gráfico 10 aponta para a diminuição do custo financeiro anual, principalmente pelo fato de se tratar de uma população que não considera a entrada de novos militares ativos.

Foram considerados custos somente aqueles relativos ao pagamento de pensões, com o saldo financeiro anual mantido negativo e tendendo a zero, até a extinção da população. 


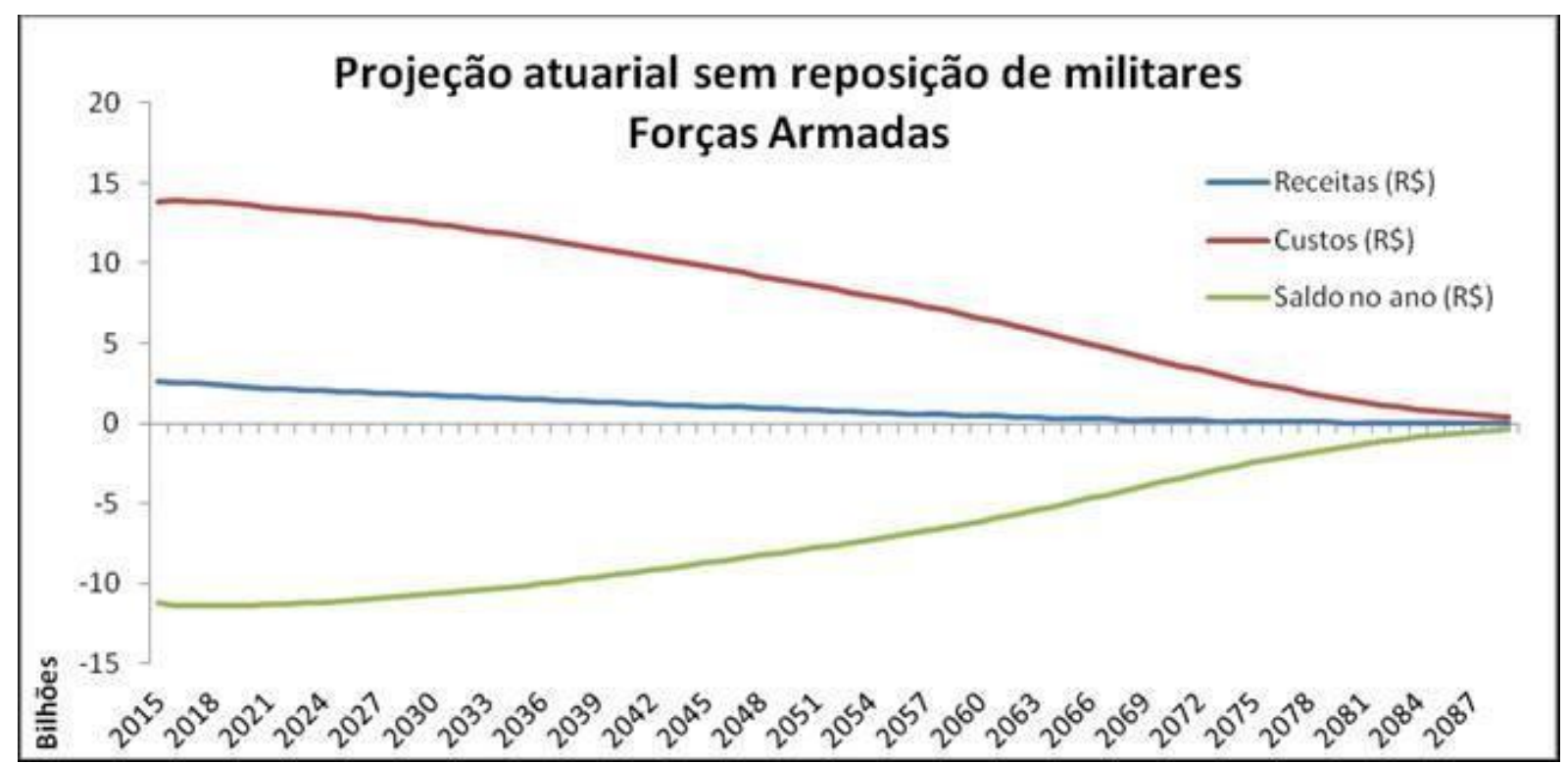

Gráfico 10. Projeção Atuarial sem reposição - Pensionistas - FFAA

Para calcular a projeção atuarial com reposição de militares da FFAA, foi utilizada como base a projeção atuarial sem reposição de militares. Desta forma, para cada militar ativo que saia do serviço ativo, seja por transferência para a reserva remunerada, reforma por invalidez ou falecimento, é incluído um novo militar no serviço ativo.

Tal projeção, expressa no Gráfico 11, demonstra no horizonte temporal de 75 anos diminuição dos custos com pensões a médio prazo e estabilização dos custos a longo prazo.

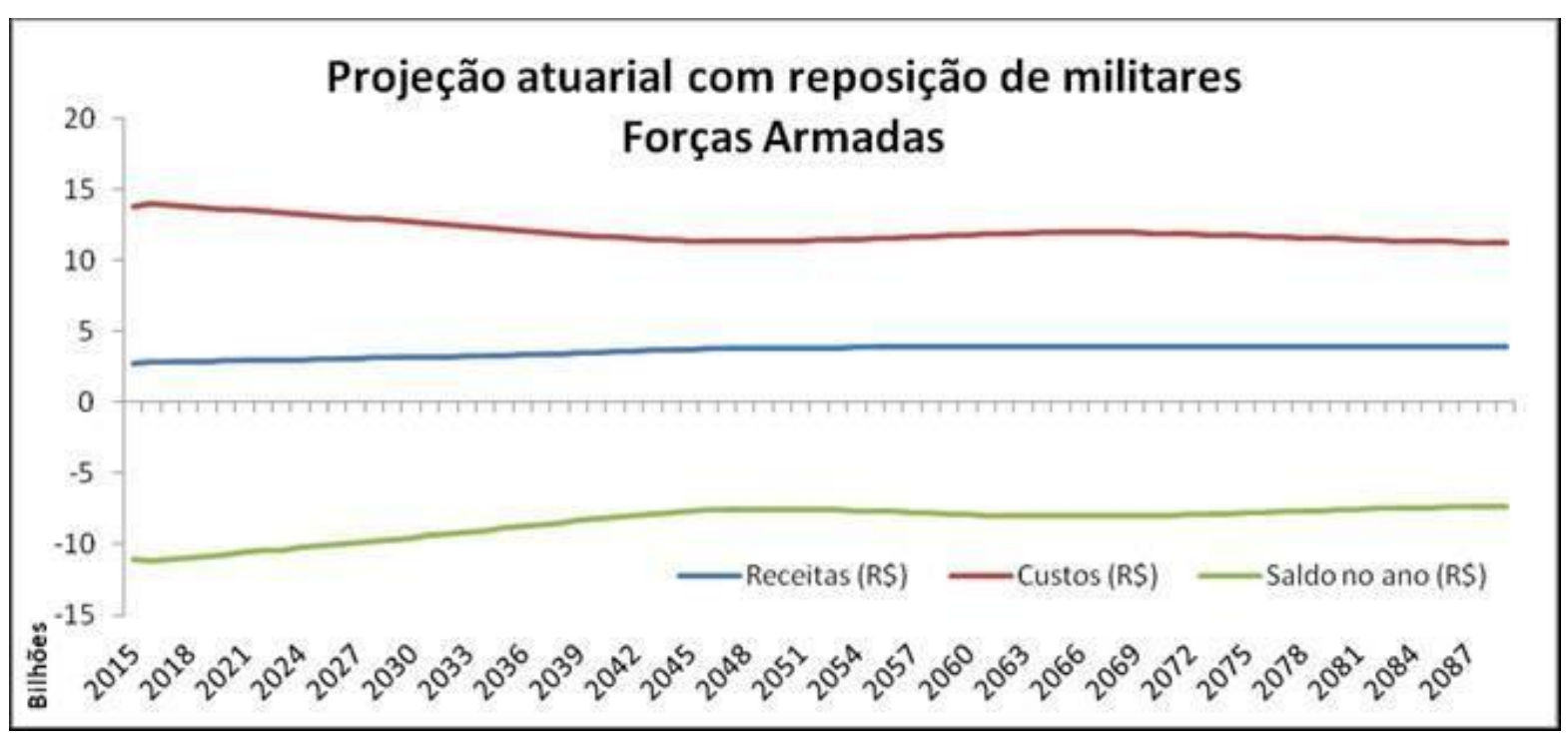

Gráfico 11. Projeção Atuarial com reposição - Pensionistas - FFAA 


\section{Conclusão}

O estudo atuarial, realizado com dados fornecidos pelas Forças em 2014, foi elaborado por meio de levantamento de dados estatísticos provenientes do BIEG e Extra-BIEG, utilizando técnicas atuariais, com respectiva legislação conexa, permitindo avaliar o valor dos compromissos da União com as Forças Armadas em relação às pensões militares.

Foram realizados testes de aderência para as tábuas biométricas pelo método quiquadrado, com agravamento e desagravamento de diversas tábuas de mortalidade, no intuito de encontrar as tábuas mais adequadas à população das Forças Armadas, conforme demonstrado no item 4.

Tais testes determinaram que as tábuas que melhor representam o comportamento dos eventos de mortalidade, entrada em invalidez e mortalidade de inválidos são respectivamente as tábuas UP-94 MT-M-ANB desagravada em 27\%, Müller e Hunter's, agravada em 82\%, para ambos os sexos.

As projeções atuariais de pensionistas sem reposição de militares ativos são decrescentes ao longo do tempo, pois a população de ativos tende a se extinguir e, consequentemente, ocorre a extinção da população de inativos e pensionistas.

Como resultado, as projeções atuariais de pensionistas com reposição de militares ativos apontam para uma redução dos custos a médio prazo e estabilidade a longo prazo, como pode ser observado no item 7 .

As informações providas por este estudo contribuem para munir a União de um conjunto de informações relativas ao custo constitucional das pensões dos militares, para correto provisionamento de recursos financeiros.

Os resultados apresentados neste estudo são sensíveis a variações de hipóteses atuariais e biométricas, da base normativa e da base cadastral. Sendo assim, recomenda-se que o sistema de pensão dos militares seja acompanhado com realização de estudos atuariais frequentes, ao menos uma vez por ano.

\section{Referências Bibliográficas}

Associação Brasileira das Entidades Fechadas de Previdência Complementar. (2014). Consolidado Estatístico. Revista Fundos de Pensão, nº 390, São Paulo: 2014

Bierwag, G. O. (1977). Immunization, duration, and the term structure of interest rates. Journal of Financial and Quantitative Analysis. December, 1.977. Pp-725- 742.

Bierwag, G. O.; Kaufman, G. G. y Toevs, A. (1983). Duration: Its Development and Use in Bond Portfolio Management. Financial Analyst Journal. July-August, 1983. Pp.15-35

Conde, Cezar Newton. Tábua de Mortalidade Destinada a Entidades Fechadas de Previdência Privada. 1991. Tese de Mestrado. (Mestrado em Ciências Atuariais). Pontifícia Universidade Católica de São Paulo, São Paulo: 1991.

Conselho Nacional de Previdência Complementar. (2013). Resolução $\mathbf{n}^{\mathbf{0}}$ 09, de 29 de novembro de 2012, Publicado no D.O.U. nº 16, de 23 de janeiro de 2013, Brasília. 
Conselho Nacional de Previdência Complementar. (2014). Resolução no 15, de 19 de novembro de 2014, Publicado no D.O.U. de 25 de novembro de 2014, Brasília.

De la Peña, J. I. (1997). El riesgo de interés en seguros y pensiones: Una aproximación actuarial. Anales del Instituto de Actuarios Españoles, 1.996, Tercera Época, Número 2. Pp.49-172

De la Peña, J. I.; Plazaola, I.I. (2008). El problema del rebalanceo en las estrategias inmunizadoras. Análisis Financiero, 2008, Número 108. Pp.66-76

Fabozzi, F. J.; Modigliani, F. y Ferri, M. G. (1996). Mercados e Instituciones Financieras. Prentice - Hall Hispanoamericana S.A. (México)

Fisher, L. y Weil, R. (1971). Coping with the Risk of Interest-Rate Fluctuations: Returns to Bondholders from Naive and Optimal Strategies. Journal of Business, October, 1.971. Pp.408-431.

Gregorio, Thierry Faria da Silva (2013). Aplicación del modelo Smith-Wilson a la estructura temporal de tipos de Interés. Efectos sobre las provisiones matemáticas de una entidad aseguradora del ramo de vida. Tese de Mestrado. Facultad de Ciencias Economicas y Empresariales. Universidad de Málaga, Málaga: 2013

Gregorio, T.F. da S.; Vianna, G.D.; D’Amato, J.S; Santos, M. dos. Imunização do Risco de Taxa de Juros de Mercado (ETTJ) em uma carteira previdenciária simulada. Revista PAGMAR, Rio de Janeiro, nº 03, p. 55-62, 2015.

Presidência da República. (1960). Lei no 3.765, de 4 de maio de 1960, Publicado no D.O.U. de 4 de maio de 1960, Brasília.

Presidência da República. (2001). Medida Provisória no 2.215-10 de 31 de agosto de 2001, Publicado no D.O.U. de 1 de setembro de 2001, Brasília.

Redington, F.M. (1952). Review of the principles of Life-Office Valuations. The Journal of the Institute of Actuaries, $n^{\circ} 78,1.952$, London. pp- 286 - 340

Reitano, R. R. (1994). Non-Parallel Yield Curve Shifts and Immunization. Proceedings of the 4th AFIR, April 20-22, 1.994. .Orlando, Florida. Pp- 427 - 455

Svensson, L. E. O. (1994). Estimating and Interpreting Forward Interest Rates: Sweden 1992 - 1994 , International Monetary Fund Working Paper, No. 114, Washington DC 